\title{
Melanism in the spider Pityohyphantes phrygianus (C. L. Koch): the genetics and the occurrence of different colour phenotypes in a natural population
}

\author{
Bengt Gunnarsson
}

Department of Zoology, University of Göteborg, Box 25059, S-400 31 Göteborg, Sweden.

In the sheetweb spider Pityohyphantes phrygianus (C. L. Koch) there is a continuous variation in dark colouration. The specimens may be divided into three main phenotype classes of colouration; pale, intermediate and melanic. Analyses of the genetic basis of colour variation in $P$. phrygianus showed that a polygenic system is probably involved. The narrow heritability of dark colouration was estimated as $0.43( \pm 0 \cdot 25)$, based on parent-offspring regression using mid-parent and mean offspring scores. A small-scale laboratory experiment indicated that the melanics may have an activity-and hence a foraging-advantage over non-melanics at low temperatures. A temporal variation in the frequencies of the three main phenotype classes was observed in a natural population in SW Sweden. This variation was due to differences between the proportion of pale and intermediate specimens in three cohorts; the proportion of melanics was low in all samples, averaging 3.7 per cent.

\section{INTRODUCTION}

Studies on the selective advantages or disadvantages associated with intraspecific variation in colouration among animals rest implicitly on the assumption that the colour variation is inherited. Among arthropods the most obvious examples of natural selection on inherited colour variants are species with a proportion of melanics in their natural populations. Good examples are certain moths, especially Biston betularius (L.), and the ladybird Adalia bipunctata L. (for reviews see Kettlewell, 1973; Muggleton, 1978; Lees, 1981). The mode of inheritance of melanism in arthropods is often governed by a one-locus mechanism with full dominance for the dark colouration, caused by one or several alleles (Kettlewell, 1973; Lees, 1981).

In order to investigate the genetics behind the variation in dark colouration in the spider Pityohyphantes phrygianus (C. L. Koch) I crossed different parent phenotypes. The knowledge about inheritance among spiders is very poor and crossing studies have so far only been used for a few species (e.g., Galiano, 1981a,b; Oxford, 1983; Stratton, 1984).

$P$. phrygianus is a spruce-living (Picea abies (L.) Karst.) sheetweb spider with a biennial lifecycle in southern Sweden. In their second winter the spiders are subadults and on mild winter days they show active foraging behaviour (Gunnarsson, $1985 a$ and unpublished). Mating occurs in May after the completion of the last moult.

An earlier study revealed a considerable variation in dark colouration among the spiders in a population in SW Sweden (Gunnarsson, 1985b). The abdominal colouration among adult and subadult specimens varied continuously from pale phenotypes with little dark colouration, through intermediates with several dark abdominal streaks, to melanic phenotypes with almost completely black abdomens (fig. 1). A similar variation appeared in all stages of the life-cycle. The classification into three main phenotype classes is, however, arbitrary and for a detailed description of the phenotypes, see Gunnarsson (1985b).

In this paper experimental results on the genetics of melanism in $P$. phrygianus and a possible selective difference between melanics and non-melanics are reported. The variation in the frequencies of the different phenotype classes in a natural population in SW Sweden is also analysed.

\section{MATERIAL AND METHODS}

The spiders were obtained from spruce branches in a vast coniferous forest about $40 \mathrm{~km}$ east of 


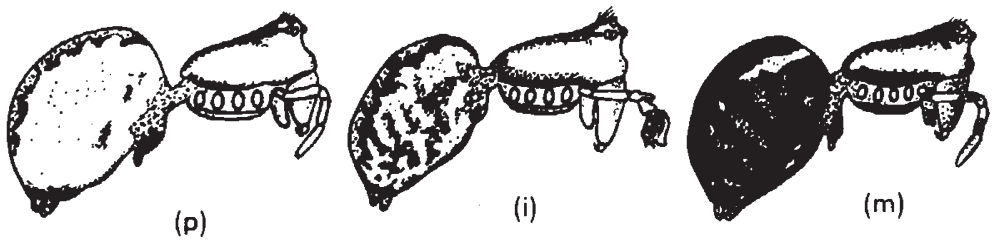

Figure 1 Lateral view of abdomen and carapace of three main phenotype classes of $P$. phrygianus: pale (p), intermediate (i) and melanic (m).

Göteborg in SW Sweden. Matings were performed between the different phenotypes in the laboratory in May 1981 and March 1984. The specimens used for the crossings were subadults when collected and they participated in only one mating experiment, except for a melanic male which mated two females (see table 1). Each female was placed in a $500 \mathrm{ml}$ plastic vial at room temperature, about $18-23^{\circ} \mathrm{C}$, under natural light conditions. They produced whitish egg sacs which were placed individually in $10 \mathrm{ml}$ plastic tubes closed with a cotton-ball and spiderlings emerged after 16-25 days.

The parent phenotypes were established by comparisons with reference specimens with a known amount of dark colouration (see Gunnarsson, 1985b) and each parent spider received a score of 1,2 or 3; pale (10-29 per cent dark abdominal colouration), intermediate (30-69 per cent) and melanic (70-100 per cent), respectively. The phenotypes of the emerged spiderlings were assessed by giving each individual a score of 1 (pale specimens), 2 (intermediates) or 3 (melanics) (Gunnarsson, 1985b). In the analyses it is assumed that specimens retain their score throughout life; observations on moulting juveniles and subadults support this assumption (Gunnarsson, unpublished).

A small-scale activity experiment was performed with subadult spiders in the laboratory at $+4^{\circ} \mathrm{C}$. This temperature is common on winter days in SW Sweden (Gunnarsson, 1985a). The laboratory was illuminated by two $40 \mathrm{~W}$ fluorescent tubular lamps of the type "warm white". Two $500 \mathrm{ml}$ plastic vials were connected by a $100 \mathrm{~mm}$ long net-funnel. This permitted the spiders to move from one vial to the other. 28 specimens were introduced on a spruce twig in one of the vials. Specimen moving from the vial in which they were introduced into the second vial were classified as "active" and the remaining spiders as "inactive". Each half hour active spiders were removed from the vials. The experiment continued for 5 hours.

Random samples from the study population were taken in autumn and spring for four generations (cohorts I-IV). Active as well as inactive

Table 1 Data from matings with different parent phenotypes; $\mathrm{p}=$ pale, $\mathrm{i}=$ intermediate and $\mathrm{m}=$ melanic. Each hatched spiderling received score 1 (pale), 2 (intermediate) or 3 (melanic) (see text). Matings $1-11$ were performed in 1981 and 12-16 in 1984. 'indicates that the same male was used in two matings

\begin{tabular}{|c|c|c|c|c|c|c|}
\hline $\begin{array}{l}\text { Mating } \\
\text { No. }\end{array}$ & $\begin{array}{l}\text { Parents } \\
\uparrow \times \delta\end{array}$ & Score 1 & Score 2 & $\begin{array}{l}\text { Offspring } \\
\text { Score } 3\end{array}$ & Total & Mean score \\
\hline 1 & $\mathrm{p} \times \mathrm{p}$ & 22 & 2 & 0 & 24 & 1.08 \\
\hline 2 & $\mathrm{p} \times \mathrm{i}$ & 16 & 11 & 0 & 27 & $1 \cdot 41$ \\
\hline 3 & $\mathrm{p} \times \mathrm{i}$ & 21 & 9 & 0 & 30 & $1 \cdot 30$ \\
\hline 4 & $\mathrm{p} \times \mathrm{i}$ & 17 & 21 & 0 & 38 & 1.55 \\
\hline 5 & $\mathrm{p} \times \mathrm{m}^{\prime}$ & 12 & 3 & 18 & 33 & $2 \cdot 18$ \\
\hline 6 & $\mathrm{i} \times \mathrm{i}$ & 32 & 1 & 0 & 33 & 1.03 \\
\hline 7 & $\mathrm{i} \times \mathrm{i}$ & 45 & 10 & 0 & 55 & $1 \cdot 18$ \\
\hline 8 & $\mathrm{i} \times \mathrm{p}$ & 33 & 3 & 0 & 36 & $1 \cdot 08$ \\
\hline 9 & $\mathrm{i} \times \mathrm{m}$ & 13 & 23 & 1 & 37 & $1 \cdot 68$ \\
\hline 10 & $\mathrm{~m} \times \mathrm{p}$ & 9 & 0 & 0 & 9 & 1.00 \\
\hline 11 & $\mathrm{~m} \times \mathrm{m}^{\prime}$ & 4 & 15 & 1 & 20 & $1 \cdot 85$ \\
\hline 12 & $\mathrm{p} \times \mathrm{m}$ & 9 & 10 & 13 & 32 & $2 \cdot 13$ \\
\hline 13 & $\mathrm{p} \times \mathrm{m}$ & 9 & 7 & 1 & 17 & $1 \cdot 53$ \\
\hline 14 & $\mathrm{p} \times \mathrm{m}$ & 6 & 8 & 16 & 30 & $2 \cdot 33$ \\
\hline 15 & $\mathrm{~m} \times \mathrm{p}$ & 12 & 4 & 15 & 31 & $2 \cdot 10$ \\
\hline 16 & $\mathrm{~m} \times \mathrm{p}$ & 1 & 2 & 2 & 5 & $2 \cdot 20$ \\
\hline
\end{tabular}


subadult specimens were included in the samples (see Gunnarsson, 1985b). The total colour distribution among the specimens was recorded in six samples taken in autumn and spring 1982-85. These spiders were classified into nine scores of dark colouration by comparisons with reference specimens (see above), and then combined into the three main phenotype classes. The proportion of melanics only was recorded in four additional samples (see table 3 ).

\section{RESULTS}

\section{The genetics of dark colouration}

The analysis of the inheritance of dark colouration is based on 16 matings performed in 1981 and 1984 (table 1). In total 461 spiderlings hatched from the egg sacs and out of these it was possible to classify 457 specimens. The genetic basis of dark colouration was examined by exploring two possible genetic models for the inheritance; (a) a singlelocus mechanism with two alleles and (b) a polygenic mechanism.

First, consider a one-locus, two-allele model. Three outcomes are conceivable in the simple case: (i) The pale and the melanic phenotypes are homozygotes, the intermediate phenotype is the heterozygote, and no dominance is involved; (ii) Incomplete or full dominance is involved; (iii) The pale and the intermediate phenotypes are identical genotypes and homozygotes, the melanics are heterozygotes, and the second homozygote results in lethality. In each of the three hypotheses analysed there was segregation of phenotypes in offspring that should not occur, and/or several cases of significant deviations from the expected segregation ratios (chi-square tests, $P<0.025$ or less). In some of the breeding data there is also heterogeneity between broods from identical parents (e.g., matings no. 5, 12, 13, 14 in table 1: $\left.\chi_{6}^{2}=16.88, P<0.01\right)$.

Hence, the one-locus, two-alleles model seems inappropriate to explain the inheritance of dark coloration in $P$. phrygianus. More elaborated onelocus models are of course possible, for instance if three or more alleles are invoked, but the present breeding data is inadequate to explore such models in detail.

The second, polygenic, model is analysed by examination of resemblance between relatives. The heritability $\left(h^{2}\right)$ in the narrow sense estimates the proportion of the total phenotypic variance that is due to the additive effects of genes (Falconer, 1981). Since all spiders used in the present study were collected from a single population and the matings were performed under similar laboratory conditions, the data were combined in the analyses.

The heritability may be estimated in several ways. First I will employ the method using parentoffspring regression. Only mean scores for male plus female offspring could be used here since sex determination of the spiderlings is impossible without chromosome analysis. For the mid-parent versus mean offspring a heritability estimate of 0.432 (S.E. 0.249) was obtained (fig. 2(a)). The significance level for the regression coefficient to be different from zero is just above 5 per cent, $t=1.708$ in the present case versus $t=1.761$ and $t=1.345$ for the 5 per cent and 10 per cent levels, respectively. The value for males versus mean offspring was 0.518 (S.E. $0.264, P<0.05$ ) (fig. $2(b))$. These two heritability values were calculated using a weighting factor to correct for unequal size of the broods (Falconer, 1963). For female parents plotted against mean offspring the calculations revealed an insignificant value of 0.008 (S.E. 0.296, $P>0.4$ ) (fig. 2(c)). (a)

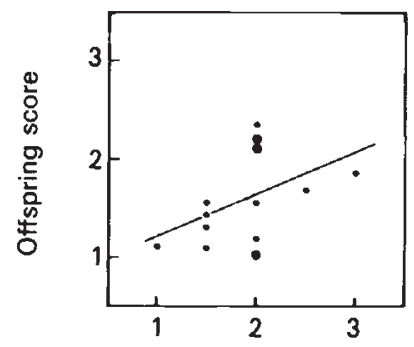

(b)

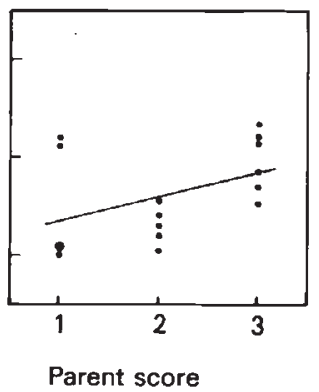

(c)

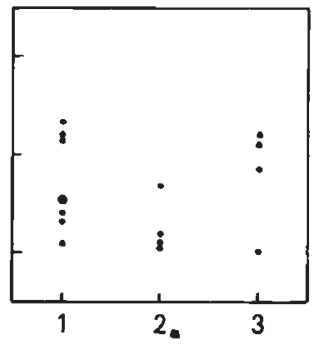

Figure 2 Heritability estimates based on parent-offspring regression (see text). Large dots denote two very close points. (a) mid-parent versus mean offspring, $h^{2}=0.43$; (b) males versus mean offspring, $h^{2}=(0 \cdot 26 \times 2)=0.52$; (c) females versus mean offspring. 
Second, the heritability value was calculated using the intraclass correlation coefficient, $t$, and for full sibs $2 t \geqslant h^{2}$ (Falconer, 1981). The intraclass correlation coefficient is defined as:

$$
t=\sigma_{B}^{2} /\left(\sigma_{W}^{2}+\sigma_{B}^{2}\right)
$$

where $\sigma_{B}^{2}$ is the between-group variance and $\sigma_{W}^{2}$ is the within-group variance. These variance components were calculated using a method described by McWhirter (1969). In the present case $\sigma_{B}^{2}$ is 0.200 and $\sigma_{W}^{2}$ is 0.352 . This means that $t$ is 0.36 and the heritability estimated is 0.72 .

Hence, there is probably a genetic component of the variation in dark colouration. At least the tentative hypothesis of a polygenic inheritance could not be refuted with present data.

\section{Activity of the phenotypes}

One hypothesis about a possible selective difference between the phenotypes was examined. In a laboratory experiment at $+4^{\circ} \mathrm{C}$ a test was performed to establish whether melanic specimens are more active than non-melanics at low temperatures. Nine melanic and 19 non-melanic (pale and intermediate specimens) subadult spiders were allowed to move freely between two plastic vials (see Material and methods). In total 57 per cent of the spiders moved. A statistically significant difference in activity between the two spider categories was found; all melanics moved but only 37 per cent of the non-melanics (table 2; Fisher exact test, $P=0.0017$, one-tailed). Melanic spiders thus seem to move more frequently at low, i.e., winter, temperatures than non-melanics. Probably the melanics absorb light energy quicker than nonmelanics and convert this energy into increased activity.

Table 2 Activity of melanic versus non-melanic spiders at $+4^{\circ} \mathrm{C}$ in a laboratory experiment (see text)

\begin{tabular}{llll}
\hline & Melanics & Non-melanics & $\begin{array}{l}\text { Total } \\
\text { number }\end{array}$ \\
\hline Active specimens & 9 & 7 & 16 \\
Inactive specimens & 0 & 12 & 12 \\
Total number & 9 & 19 & 28 \\
\hline
\end{tabular}

\section{Phenotype frequencies in a natural population}

A continuous distribution in the amount of dark abdominal colouration among the subadult specimens in six samples investigated from the study population in SW Sweden was observed (fig. 3,

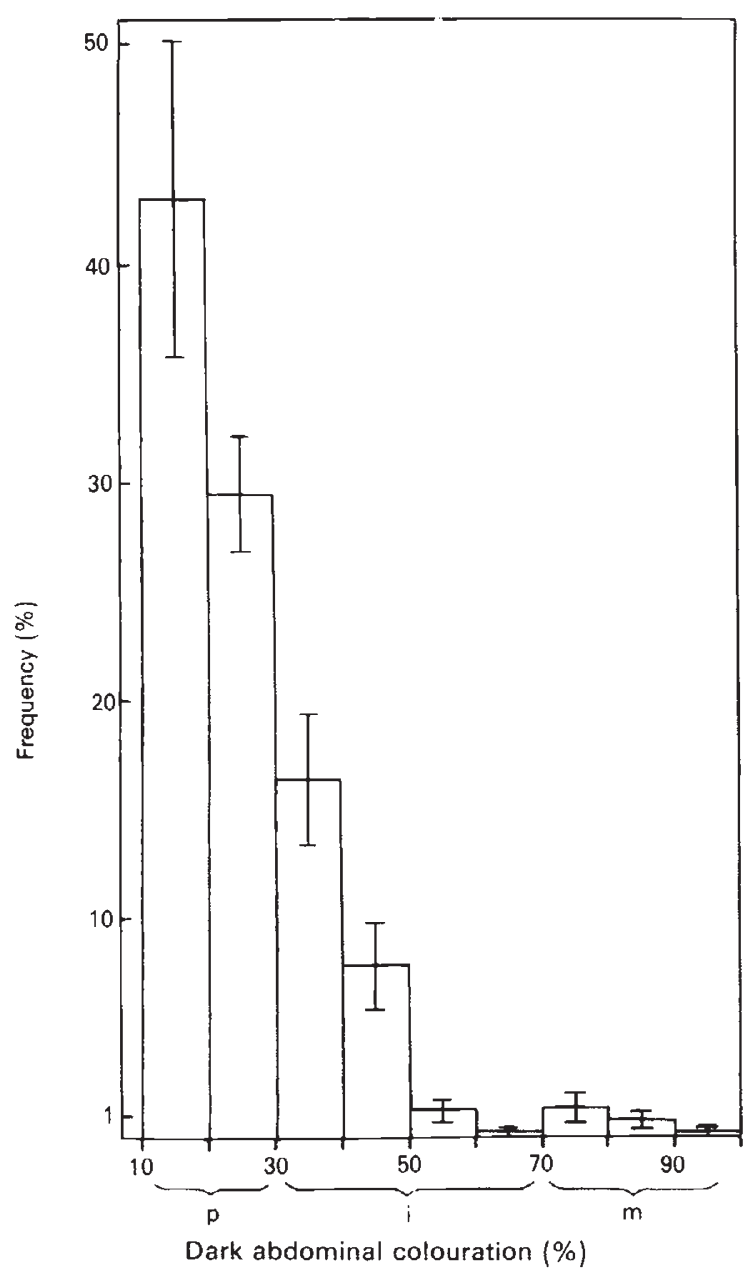

Figure 3 Mean frequencies ( \pm S.E.) of nine phenotype classes among subadult spiders in a natural population. Based on six samples totalling 489 specimens (see table 3 ). Three main phenotype classes are denoted by p (pale), i (intermediate) and $m$ (melanic).

see also Gunnarsson, 1985b). The pale phenotype was common, on average it made up 72.5 per cent of the specimens in the samples analysed. The intermediate and melanic phenotypes made up $25 \cdot 5$ per cent and $2 \cdot 2$ per cent, respectively.

In order to detect any spatial or temporal variation in the frequencies of the three main phenotype classes, six samples from three cohorts were analysed (II-IV, see table 3 ). Since the proportion of melanics was low in all samples, the intermediates and the melanics were combined into a single class in the statistical tests.

No spatial variation was observed between the phenotypes in samples taken on the same day at two different sites in the study area (spring and 
Table 3 Temporal variation in the proportion of melanics among subadult spiders in a natural population in SW Sweden. In the samples marked with an asterisk nine phenotype classes were assessed (see fig. 3). In the spring sample in 1985 no melanic spider was found among 64 specimens collected

\begin{tabular}{|c|c|c|c|c|c|}
\hline Date & Cohort & $\begin{array}{l}\text { Total number } \\
\text { in sample }\end{array}$ & $\begin{array}{l}\delta \sigma \\
\% \text { melanics }\end{array}$ & $\begin{array}{l}\$ \% \\
\% \text { melanics }\end{array}$ & $\begin{array}{l}\delta \precsim+q q \\
\% \text { melanics }\end{array}$ \\
\hline 6 Oct. 1981 & I & 123 & $4 \cdot 7$ & $6 \cdot 3$ & $5 \cdot 7$ \\
\hline 30 Sep. $1982^{*}$ & II & 62 & $4 \cdot 5$ & $2 \cdot 5$ & $3 \cdot 2$ \\
\hline 5 Oct. 1982 & II & 242 & $3 \cdot 0$ & $4 \cdot 3$ & $3 \cdot 7$ \\
\hline 5 Apr. $1983^{*}$ & II & 50 & 0 & $2 \cdot 3$ & $2 \cdot 0$ \\
\hline 2 Apr. $1984^{*}$ & III & 63 & 0 & $2 \cdot 4$ & 1.6 \\
\hline 28 Sep. $1984^{*}$ & IV & 127 & $8 \cdot 3$ & $3 \cdot 3$ & $4 \cdot 7$ \\
\hline $15 \& 19$ Apr. 1985* & IV & 64 & 0 & 0 & $(<1 \cdot 6)$ \\
\hline
\end{tabular}

autumn 1984; $G=1 \cdot 52, P<0 \cdot 3 ; G=1 \cdot 68, P<0 \cdot 2$, respectively). Neither there was any significant difference between autumn and spring samples within each of the three cohorts (II, $G=1 \cdot 31$, $P<0.3$; III $, G=1.93, P<0.2$; IV $, G=1.59, P<$ $0 \cdot 3)$. However, when considering the phenotype proportions in the three cohorts there was a significant heterogeneity between them (fig. 4; $\left.G_{H(2)}=29.95, P<0.001\right)$. This heterogeneity was confirmed by pairwise tests (cohort II versus III, $G=7 \cdot 11, P<0 \cdot 01$; II versus IV $, G=28 \cdot 88, P<$ $0 \cdot 001$; III versus IV, $G=9 \cdot 46, P<0 \cdot 01)$.

I used a 3-way G test (Sokal and Rohlf, 1981) to analyse if there was any interaction, i.e., dependence, between cohort $(C)$, season $(S)$ and the frequencies of the nine colouration classes $(F)$. No such complete three-way interaction was found $\left(G_{C S F}<14.94, \mathrm{df}=8, P>0.05\right)$ and there seems to be an independence between season and colouration frequency $\left(G_{S F(C)}=18.34, \mathrm{df}=12, \quad P>\right.$ $0 \cdot 10)$. However, the colour distribution was not independent of cohort $\left(G_{C F(S)}=73 \cdot 32, \mathrm{df}=16\right.$, $P<0 \cdot 001$ ), as indicated by the analysis above.

Unfortunately it was not possible to make an assessment of the phenotype classes in all samples investigated. In four samples the specimens collected were used in different experiments and only the proportion of melanics was recorded (table 3 ). The melanics made up between 0.8 and 7.7 per cent of the total population, but in spring 1985 no melanics at all were recorded (table 3 ). The overall mean was 3.7 per cent melanics, which is higher than the value obtained from the six samples in which the total colour distribution was assessed. No difference in the proportion of melanics between the sexes was observed (Wilcoxon matched-pairs signed-ranks test, $T=12, P>0.05$; only samples with 20 or more specimens of each sex were used). Further, there was no trend in the temporal variation of the proportion melanism when autumn and spring samples were compared (Mann-Whitney $U$ test, $U=8, \quad P=0.476$ ). However, in autumn 1983 there was a significant increase in the proportion of melanics from September $(0.8$ per cent $)$ to October $(7.5$ per cent $)$ $(G=8 \cdot 04, P<0 \cdot 01)$. This increase is difficult to interpret without knowledge about the total distribution of phenotypes.

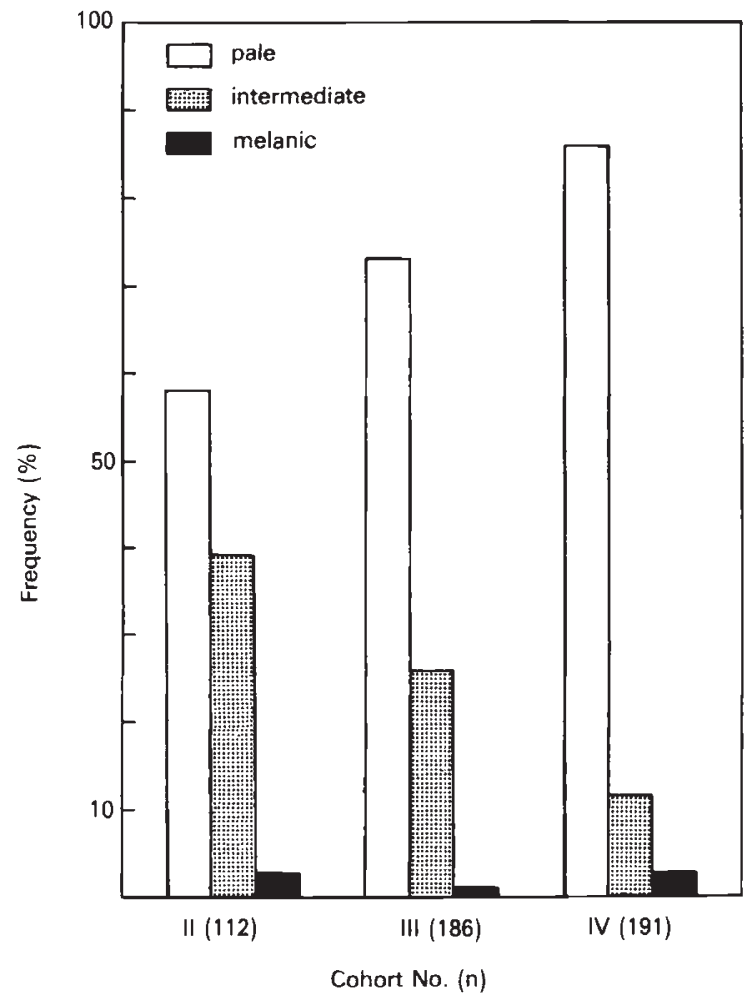

Figure 4 Frequencies of the three main phenotype classes (pale, intermediate, melanic) in pooled samples of cohorts II, III, IV (see table 3). 


\section{DISCUSSION}

\section{The inheritance}

The continuous variation of dark colouration in $P$. phrygianus, from pale to melanic phenotypes (fig. 2 and Gunnarsson, 1985b), indicates that the melanics should not be treated as a distinct genetic morph. Thus a tentative hypothesis about a polygenic mode of inheritance seems reasonable. This is contrary to what is known about inheritance of melanism in most other arthropods. Usually the melanic forms are inherited as simple Mendelian dominants or recessives; most known examples are found among moths (Kettlewell, 1973; Lees, 1981). Melanism is nearly always a fully dominant character. Indeed, so strong is the dominance in Biston betularius that crosses for five generations between British melanics and Finnish nonmelanics (melanics have never been observed in Finland) did not produce any significant colouration difference between heterozygous and homozygous moths (Mikkola, 1984).

The absence of dark (score 3 ) offspring in the mating experiments between non-melanic spiders (matings no. 1-4, 6-8 in table 1) suggests involvement of major genes. However, the data obtained did not support the hypothesis that melanism in $P$. phrygianus is governed by simple Mendelian genetic mechanisms. Nor did the experiments show any indications of full dominance, although in some of the matings there were more lightcoloured (score 1) offspring than would be expected if no dominance at all is involved (matings no. $6,7,9)$.

\section{The heritability}

For a quantitative character the heritability in the narrow sense $\left(h^{2}\right)$ shows the proportion of the phenotypic variance that is attributable to additive effects of genes. However, different methods to obtain the $h^{2}$ value can reveal estimates which may differ considerably. In the present case the regression coefficient between mid-parent and mean offspring will produce the best estimate, 0.43 (see fig. 2), since only the mean value for male plus female offspring is available. In a one-parent regression only offspring of the same sex as the parent should normally be included. The reason for the large discrepancy between the heritability estimates obtained from the regressions using male $\left(h^{2}=0.52\right)$ and female $\left(h^{2}=0 \cdot 01\right.$, not significant $)$ values, is not known. A possible explanation is that the dark colouration is inherited as a sex- linked character. If this hypothesis is correct there should be a significant difference in mean offspring score comparing matings between pale females $\times$ melanic males $(p \times m)$, and melanic females $\times$ pale males $(m \times p$, see table 1$)$. This is, however, not the case; mean score for $p \times m$ is 2.04 and for $m \times p$ 1.77 (Mann-Whitney $U$ test, $U=4, P=0.314$, one-tailed).

The full-sib estimate includes an environmental covariance which is often considerable and therefore sets an upper limit to the heritability (Falconer, 1981). This means that the value obtained of 0.72 is most probably too high.

A factor which may cause an additional variance is the classification into three scores. Some spider species are known to change their abdominal colouration in relation to the environment (Blanke and Merklinger, 1982), although I have no data for $P$. phrygianus that suggest any strong environmental impact on the phenotypes. Moreover, using only three scores permits some environmental influence within each class without alteration of a given score. Only a small proportion, about 5 per cent, of the examined offspring was found to be intermediate between the three categories used for scoring (Gunnarsson, 1985b).

\section{The phenotypes in a natural population}

Among arthropods melanic specimens may raise their body temperature more rapidly than nonmelanics (see e.g., Casey, 1981; Brakefield and Willmer, 1985). This means that melanics are able to prolong their activity periods and thereby increase the time available for foraging, mating, ovipositing etc. at low ambient temperatures (Roland, 1982; Brakefield, 1984). The advantage of an increased diel activity is especially prominent in cold environments (Roland, 1982).

According to the small-scale laboratory experiment there seems to be a difference in activity between melanic and non-melanic $P$. phrygianus specimens at $+4^{\circ} \mathrm{C}$ (table 2 ). The high activity level in the experiment may in part be an effect of the high experimental density used. However, the difference in activity between the spider categories should still reflect their propensity to move at a low temperature. Subadult spiders in the study population are active and foraging on spruce branches through autumn and winter on mild days, when the ambient temperature is about $+4^{\circ} \mathrm{C}$ or more (Gunnarsson, 1985a). Since spiders in natural populations are often energy-stressed (e.g., Wise, 1979; Spiller, 1984), the melanics may gain increased fitness in the breeding season by their 
relative high activity-and hence increased time for foraging - in late autumn and winter.

However, the possible profits of an increased winter activity among melanics may be counterbalanced by heavy bird predation. In the study area bird predation on overwintering spruce-living spiders causes at least 20 per cent winter mortality (Askenmo et al., 1977; Gunnarsson, 1983). Experimental studies have revealed that increased spider activity leads to increased risks of being eaten by birds (Avery and Krebs, 1984). Hence, on mild days in mid and late winter, active melanic specimens may be preyed upon by birds at a much higher rate than non-melanics. Consequently, being melanic does not seem to be of great advantage in the study population. The proportion of melanics is stable at a low percentage (fig. 3 and table 3 ).

With the present results it is difficult to explain the heterogeneity in colouration distribution among the cohorts (fig. 4). It is not known if the variation is caused by deterministic forces, e.g. selection, or by stochastic events. Further studies are needed to evaluate the biological significance of the differences in the proportion of pale and intermediate specimens between cohorts. In the polymorphic spider Enoplognatha ovata (Clerck) there is evidence for natural selection acting on the different colour morphs in British populations (Oxford, 1985; Oxford and Shaw, 1986).

Acknowledgments I am most grateful to A. Andersson, P. M. Brakefield, R. $\AA$. Norberg and G. S. Oxford for many valuable suggestions on earlier versions of the manuscript. The Department of Genetics, University of Göteborg, supplied me with Drosophila flies. The study was supported by grants from the Wilhelm and Martina Lundgren Foundation, the Adlerbert Foundation and the Kungl and Hvitfeldtska Stipendieinrättningen.

\section{REFERENCES}

ASKENMO, C., VON BRÖMSSEN, A., EKMAN, J. AND JANSSON, C. 1977 . Impact of some wintering birds on spider abundance in spruce. Oikos, 28, 90-94.

AVERY, M. I. AND KREBS, J. R. 1984. Temperature and foraging success of Great Tits Parus major hunting for spiders. Ibis, 126, 33-38.

BLANKE, R. AND MERKLINGER, F. 1982. Die Variabilität von Zeichnungsmuster und Helligkeit des Abdomens bei Araneus diadematus Clerck und Araneus marmoreus Clerck (Arachnida: Aĩaneae). Z. zool. Syst. Evolut.-forsch., 20,63-75.

BRAKEFIELD, P. M. 1984. Ecological studies on the polymorphic ladybird Adalia bipunctata in the Netherlands. II. Population dynamics, differential timing of reproduction and thermal melanism. J. Anim. Ecol, 53, 775-790.
BRAKEFIELD, P. M. AND WILLMER, P. G. 1985. The basis of thermal melanism in the ladybird Adalia bipunctata: Differences in reflectance and thermal properties between morphs. Heredity, 54, 9-14.

CASEY, T. M. 1981. Behavioural Mechanisms of Thermoregulation. In Heinrich, B. (ed.) Insect Thermoregulation, John Wiley \& Sons, New York, pp. 79-114.

FALCONER, D. S. 1963. Quantitative Inheritance. In Burdette, W. J. (ed.) Methodology in Mammalian Genetics, HoldenDay Inc., San Francisco, pp. 193-216.

FALCONER, D. S. 1981. Introduction to Quantitative Genetics, 2nd ed. Longman, London

galiano, M. E. 1981 a. Revision del genero Phiale C.L. Koch, 1846 (Araneae, Salticidae) III. Las especies polimorficas del grupo mimica. J. Arachnol., 9, 61-85.

Galiano, M. E. 1981 b. Revision of the genus Phiale C.L. Koch 1846 (Araneae, Salticidae) IV. The polymorphic species of the gratiosa group. Bull. Br. arachnol. Soc., 5, 205-216.

GUNNARSSON, B. 1983. Winter mortality of spruce-living spiders: effect of spider interactions and bird predation. Oikos, 40, 226-233.

GUNNARSSON, B. 1985a. Interspecific predation as a mortality factor among overwintering spiders. Oecologia (Berl.), 65 , 498-502.

GUNNARSSON, B. $1985 \mathrm{~b}$. Phenotypic variation in dark coloration in Pityohyphantes phrygianus (C. L. Koch) (Araneae: Linyphiidae). Bull. Br. arachnol. Soc., 6, 369-374.

KETTLEWELL, H. B. D. 1973. The Evolution of Melanism. Clarendon Press, Oxford.

LEES, D. R. 1981. Industrial Melanism: Genetic Adaptation of Animals to Air Pollution. In Bishop, J. A. and Cook, L. M. (eds.) Genetic Consequences of Man Made Change, Academic Press, London, pp. 129-176.

MCWHIRTER, K. 1969. Heritability of spot-number in Scillonian strains of the meadow brown butterfly (Maniola jurtina). Heredity, 24, 314-318.

MIKKOLA, K. 1984. Dominance relations among the melanic forms of Biston betularius and Odontoptera bidentata (Lepidoptera, Geometridae). Heredity, 52, 9-16.

MUGGLETON, J. 1978. Selection against the melanic morphs of Adalia bipunctata (Two-spot ladybird): A review and some new data. Heredity, 40, 269-280.

OXFORD, G. S. 1983. Genetics of colour and its regulation during development in the spider Enoplognatha ovata (Clerck) (Araneae: Theridiidae). Heredity, 51, 621-634.

OXFORD, G. S. 1985. A countrywide survey of colour morph frequencies in the spider Enoplognatha ovata (Clerck) (Araneae: Theridiidae): evidence for natural selection. Biol. J. Linn. Soc., 24, 103-142.

OXFORD, G. S. AND SHAW, M. W. 1986. Long-term variation in colour-morph frequencies in the spider Enoplognatha ovata (Clerck) Araneae: Theridiidae): natural selection, migration and intermittent drift. Biol. J. Linn. Soc., 27, 225249.

ROLAND, J. 1982. Melanism and Diel Activity of Alpine Colias (Lepidoptera: Pieridae). Oecologia (Berl.), 53, 214-221.

SOKAL, R. R. AND ROHLF, F. J. 1981. Biometry, 2nd ed. Freeman, New York.

SPILLER, D. A. 1984. Competition between two spider species: experimental field study. Ecology, 65, 909-919.

STRATTON, G. E. 1984. Differences in maturation rates of Schizocera ocreata, Schizocera rovneri, $F_{1}$ and $F_{2}$ hybrids and backcross progeny. Bull. Br. arachnol. Soc., 6, 193-199.

WISE, D. H. 1979. Effects of an Experimental Increase in Prey Abundance Upon the Reproductive Rates of Two OrbWeaving Spider Species (Araneae: Araneidae). Oecologia (Berl.)., 42, 289-300. 